\title{
The Difference Culture Makes
}

\author{
Paul Wason
}

\begin{abstract}
The dawn of culture and its subsequent elaboration is one of the most important developments in the history of life. It is now recognized that culture, at least in a minimalist sense of behavioral traditions shaped by social learning, is found widely throughout the animal kingdom. And this fact, perhaps ironically for those of a reductionist bent, has made possible new understandings of just how distinctive humans are, especially in terms of symbolic thought, cooperativity far beyond genetic relatedness, the cumulative nature of our cultures, and our pervasive sense of transcendence. Yet, nearly 150 years after Tylor's Primitive Culture, we are still coming to appreciate in sometimes surprising new ways how the phenomenon of culture is transforming this planet. I suggest that despite the apparent pervasiveness of the concept, or at least the word, in both scholarly and everyday discourse, we have yet to appreciate the full potential of the concept of culture as an intellectual tool. Through brief exploration of five different situations in which it is useful, I hope to illustrate the importance of the phenomenon and show the untapped potential of the concept.
\end{abstract}

Each of us hears the word 'culture', and likely enough uses it, several times per day. It is so much a part of our thinking that we hardly even notice it. This in itself suggests its importance, and that we do, at some level, recognize how deeply the culture we are a part of influences our lives. Here I take a step back and ask what difference it makes that we have cultures at all, that humans are cultural beings, according to both science and theology, and that our enhanced capacity as culture-makers is what makes us unique and gives us our special role in creation. I believe the phenomenon of culture has made a greater difference to the course of life on our planet than we generally appreciate, and propose as well that for all our use of the word, we have yet to take full advantage of the concept in scientific investigation. To illustrate, I explore here several points at which remembering culture can help to solve seemingly intractable problems in science. This is not a systematic review, but I do hope it provides a sufficient range of examples to spark further thought on how the world has developed differently since the advent of culture-bearing animals, as well as an exploration of other ways in which we can better understand ourselves as human creatures through understanding the difference culture makes.

This is not just a matter of helping the world at large to appreciate anthropology better, much needed though that is. The value of a deeper understanding of

Paul Wason is the Vice President of Life Sciences and Genetics at the John Templeton Foundation. Author email: pwason@templeton.org. culture's significance stems from two important facts. First, culture is so central to being human that it is not possible to really understand ourselves without knowing as much as we can about it: what culture is, how it works and the difference it makes. Second, cultures change. We change cultures. This ability of ours is an exciting opportunity and a great danger at once, and it wouldn't hurt to better appreciate how it works. I do not mean this negatively, not completely negatively; it would only make sense to oppose culture change if we were living now in the best of all possible worlds. But in our age, faced with wondrous technological potential, vast and multiplying scientific knowledge, but also an immense burden of unintended consequences from previous human activities and a responsibility of stewardship for the environment, it seems all the more valuable to seek better appreciation of how and in what ways our cultures in their many parts, not just their technologies, are of great significance. And of the fact that they can be changed.

Sounds simple, perhaps even obvious. Yet in the manner of water to a fish, it is hard for humans to imagine life without culture, and if we can't picture an uncultured life, we are bound to miss ways in which culture makes a difference. I begin with two examples of conversations about culture to help illustrate the complications. In the first, Amos Yong begins his book Beyond the Impasse: Toward a Pneumatological Theology of Religions with this conversation he had with his parents soon after they moved to the US from Malaysia. 
Amos: So, what is our culture? Chinese? Malaysian? American?

Parents: None of the above; we're Christians

Amos: Christians? But we're also Chinese, right? And I'm a Malaysian citizen, right?

Parents: Well, yes. But since we're Christians, we pay supreme allegiance to Jesus, not to the norms or conventions of any particular culture.

Amos: So, we're just Christians? We don't belong to any culture?

Parents: Well, we're Christians, and we belong to the Christian culture. (Yong 2003:9)

Yong, a theologian, goes on to use the idea of culture in a fascinating exploration of what religion is, but I simply wish to plant this conundrum in our minds to illustrate how it can seem so easy yet be so difficult to speak clearly about culture. Is there really such a thing as a "Christian culture?" Or for that matter, a Malaysian Culture? And if so, is one a part of it in virtue of being a Malaysian citizen? Does each person have one culture? And if so is it the same as that of other members of his or her family, village, nation?

Once upon a time, not long ago, one could hear people saying American culture is a Christian culture. Maybe it was, maybe it wasn't, but it surely isn't now, say the authors of several books on religion and culture in the US that, perhaps not coincidentally, appeared at nearly the same time early this year (Dreher 2017; Chaput 2017; Esolen 2017). Which brings us to the second example of a conversation about culture that illustrates its complications. Andy Crouch has also written a great deal about culture, its relation to creativity and human purpose, and in light of this, how Christians should relate to the cultural world in which we find ourselves (Crouch 2013). He points out (Crouch 2016) that while we often speak of "the culture"-as in, the culture is becoming more secular, or in urging each other to better engage the culture, we commonly use a broad, even generic version of the concept, making it hard to know exactly what it is we think we should engage. Are we engaging American culture, suburban Philadelphia culture, university culture?
Moreover, when we consider culture, to what extent are we engaging it from outside rather than as members? My guess is Amos' parents would see themselves engaging their own culture from outside. I think there is some value in this, though it can't be the whole approach we take as Christians. Crouch advises us to think carefully about what kinds of things we might mean or not mean when we talk about culture. When, in Romans, Paul calls us to resist being "conformed to this world," is he saying Christians should create a culture of our own? This is an idea Rod Dreher explores in interesting ways, drawing on insights from church history (2017). If so (even if not, come to think of it), a better understanding of culture, of how it works, and of how we ourselves are shaped by cultural influences around us, would help us to engage in our divinely appointed task of culture-making more effectively.

These conversations barely begin to express the range of issues involved in understanding culture as a part of our current circumstance in the world and its future. I don't propose to resolve all of the dilemmas except to say that through conversations in response to my questions above, we may well add value to the important conversation about Christians and trends in American life just mentioned, as well as what Christian community is, or could be, in turn.

In order to have the conversation, it would seem that we should first agree on what we mean by 'culture'. However, I am not so sure that a single definition is necessary. Discussions can benefit, I believe, from such unresolved questions. I realize that sounds more than a little flaky in the 'it doesn't matter what you believe as long as you are sincere' sort of way. Careful definition is useful for focused discussions. And we can certainly get much more insight from conversations about culture if we think a little harder about what we mean in each instance. Concerning discussions about Christianity and American culture, very likely it is not just political disagreements that make discussions complicated but also unrecognized differences in our views about culture, different meanings implied, and perhaps especially a lack of appreciation of how cultures change. With all this I agree. But my point is that insisting more generally on one definition for all conversations has not worked in the past even within academic anthropology and likely would reduce the idea's usefulness now.

\footnotetext{
${ }^{1}$ Dreher proposes that like St. Benedict, who developed communities and practices to help Christians remain faithful in the midst of turmoil and confusion as the power of Rome waned, orthodox Christians do something similar today rather than depending on such things as changing the political system. The "Benedict Option" he proposes might take any number of forms, but overall it is "a strategy that draws on the authority of Scripture and the wisdom of the ancient church to embrace 'exile in place' and form a vibrant counterculture" (2017:18). I do not think one needs to agree with his assessment of the problem-which I expect some will find unduly alarmist-to see great value in Dreher's ideas for how to forge Christian lives and communities that are rich, creative, and helpful for others. As he notes: "We cannot give the world what we do not have" (19).
} 
Following my own seemingly mixed advice, I would pause here for a brief discussion of what culture is-yet without suggesting there is one definition that can suffice for all useful explorations of the subject, even, perhaps, for every page in this article. In 1952 Kroeber and Kluckhohn famously undertook a "critical review" in which they went over 164 concepts and definitions. In the introduction to this work, which is not nearly as dull as it sounds, they quote Lawrence Henderson-a biologist who wrote, in 1913, an important work on 'the fitness of the environment' for life-who was fond of telling his students "In science, any classification is better than no classification as long as you don't take it too seriously." With that in mind, and ignoring not just Tylor but virtually all of those 164 definitions for the moment, I offer a definition of culture for current purposes as a set of socially transmitted information that affects nearly all our behavior. You needn't take it too seriously. For many purposes, you will very likely want to add to it; I appreciate that it is a bare-bones definition. While it does follow Geertz at least a few steps down the path-he saw culture as having a "double aspect" that included patterns for behavior as well as patterns of behavior (Geertz 1973:93)-for reasons that will become clear, it ignores an essential idea of Kroeber and Kluckhohn's own $165^{\text {th }}$ definition, as well as that of Geertz and many others, that these patterns are acquired and transmitted through symbols. Given this rough sense of how I will use the word, we return to the original question, why should we care-or more formally, what difference does culture make? I offer a series of five situations in which remembering culture assists us to understand ourselves and our world better, a couple giving more emphasis to the phenomenon and its impact on the world, the others emphasizing the concept and its usefulness for intellectual insight.

\section{Culture Makes Humans Different}

Our cultures have made it possible for humans to become a dominant species on this planet, for better and for worse. Other dominant species, like certain kinds of bacteria, have succeeded by being able to reproduce every 20 minutes or so and by being able to live in what most humans would consider uncomfortable places. Culture works differently.

One major difference is that it allows for rapid behavioral change compared to biological evolution. The biological evolution of new traits can take many generations. No big deal if your generations are 20-odd minutes long and you merely need to become immune to antibiotics. But in addition to having somewhat longer generations, we like to pursue goals that may include, but also that go well beyond, surviving in great numbers. Cultures are much more important for humans than they could ever be for bacteria, which is probably just as well.

New cultural traits can also be transmitted from any one to any other living conspecific. This can be from children to parents (if the parents aren't careful), or even indirectly, as from Aristotle. In practice, it's more complicated, but also more interesting, than this wellknown fact suggests. Still, at the moment, cultural transmission is no better understood by scholars than Aristotle is by the rest of us. For this reason, much research is underway which promises to immensely deepen our understanding of the difference culture makes. Consider just one element of social learning. While it has important (and to most of us rather obvious) advantages over individual trial and error discovery, it does come with risks. The most important is the possibility of acquiring misinformation, especially if one is too trusting or otherwise insufficiently careful about the source of information. A number of researchers are now working on the question of how this adaptive problem is solved, and in what ways humans approach it similarly to, or differently from other animals. What has been discovered so far consistently shows that animals do appear to have strategies guiding what kinds of information is learned from whom and under what conditions, strategies known variously as transmission bias (Boyd and Richerson 1985) or social learning strategies (Laland 2004).

Several recent studies show both the complexity of social learning and its importance. One study considered the seemingly odd fact that while chimpanzees are cultural beings (discussed more below), and while they seem to be highly innovative, they rarely create new cultural traditions from individual novel behaviors, and therefore these novel behaviors rarely become widely adopted even among local groups. Previous studies found that most novel behaviors come from low-ranking individuals (which may be more like the situation among humans than many of us would tend to assume). It is also wellappreciated that social learning among chimpanzees primarily consists of copying, rather than, say, active teaching. In a series of recent studies, Kendel, Whiten, Watson and colleagues have added some very interesting discoveries. In particular, they have found that chimpanzees preferentially copy from the most dominant individuals (Kendal et al. 2015; Watson et al. 2017). Probably to keep from being wacked in the head. ${ }^{2}$ That is, they don't copy as much from the more

\footnotetext{
${ }^{2}$ More specifically low-ranking individuals without previous experience on a task-thus more in need of information-copied much more often from higher-ranked individuals than from other low-ranked individuals. Higher ranking individuals did little copying of
} 
creative individuals in the group. This suggests it is not so much lack of creativity that holds chimpanzees back from cultural evolution as the issue of how information is transmitted socially. ${ }^{3}$ This is likely reinforced among chimpanzees by other elements of their findings "that indicate a 'copy when uncertain' bias. This contrasts with a tendency of children, in some studies, to be influenced by social information even when wellinformed" (Kendel et al. 2015:69). That is, chimpanzees are very selective about when they copy, not just about from whom they copy. Human children often seem willing to copy even when they already know the answer. This seems-and may be-inefficient, but the main point here is that among humans, social transmission of ideas and information is a much more extensive and active process than is likely in other primates, and that fact is important for the development of complex cultures.

A third well-appreciated, but nevertheless fundamentally important difference culture makes is that culture increases behavioral flexibility. People can invent new approaches to living, and these innovations spread rapidly when they are perceived to be of value, or maybe even just because they are interesting. This has been going on a long time, from the spread of Homo erectus around the world, even moving into cold regions of the earth despite a lack of fur, to the even more rapid spread in the $20^{\text {th }}$ century of carbonated beverages and then the internet to the uttermost parts of the earth.

Then, among humans, at least, the closelyconnected phenomenon known as cumulative culture further increases this behavioral flexibility so that it seems, and may be, that culture offers nearly endless possibilities. Cumulative culture is not simply the addition of more and more cultural traits to a species repertoire, but involves cultural elements building on one another. It is possible that there was a time when certain technologies were so simple that one individual knew how to mine iron ore, smelt it, forge a sword and be a great warrior. But most contemporary technology is far too complicated for that, primarily a result of the process of building on and refining ideas and behaviors over many generations. This cumulation has been greatly aided by the advent of what Merlin Donald (1991:269ff.; Renfrew and Scarre 1998) calls "external symbolic storage" beginning by at least 40,000 years ago-from cave paintings to e-books. Writing, in particular, is a cultural development that has made possible many others, and greatly aids our ability to build our new ideas on old ones, vastly multiplying possibilities.

Possibilities are immense, but we all appreciate that some are harder to instantiate than others-some perhaps harder for any human, others simply harder for people of one culture than for people of another. For by shaping our thinking at a deep level, cultures can also make certain thoughts more difficult to access, just as it makes some far easier. This is what leads to the question with which Charles Taylor begins his great work, The Secular Age: "why was it virtually impossible not to believe in God in, say, 1500 in our Western society, while in 2000 many of us find this not only easy but even inescapable?" (Taylor 2007:25). The answer is in the difference that culture makes.

At a different and I expect more contentious level, Eduardo Kohn proposes that we need to take seriously the possibility that what we consider plausible ontologies, elements of and limits to reality, can be constrained by our culture at a deeper, less historicallycontingent level than Taylor's admittedly profound concern. We are in some ways limited by our tendency to imagine that all possible thinking is similar to our own specific approaches to thinking. Humans think through language. But are there kinds of human thought that are non-linguistic? And if there are any non-linguistic entities capable of thinking, what would that look like?

My argument is that we are colonized by certain ways of thinking about relationality. We can only imagine the ways in which selves and thoughts might form associations through our assumptions about the forms of associations that structure human language. And then, in ways that often go unnoticed we project these assumptions onto nonhumans. (Kohn 2013:21)

Naturally, not being possessed of human language, these nonhumans come up short, and for those of us in contemporary Western cultures, at least, probably others as well, it doesn't immediately make sense to speak as do the people Kohn lived among in Avila, Ecuador, for whom it is important to understand how forests think. Kohn wants us to take this seriously in ways that go beyond the usual anthropological appreciation for the thought systems of traditional peoples.

any kind. This may be because of having other ways of gaining new food resources than learning the novel foraging techniques presented in these studies, and thus may not suggest high ranking chimpanzees avoid copying generally, but the latter is also possible.

As an aside, and as noted many times before, many human cultural traits, such as peer review in the sciences, suggest that it isn't just chimpanzees that work this way. Although I say this jokingly, it raises some serious points worth considering in terms of how social transmission of cultural information works; perhaps we humans could take full advantage of what we know about the difference culture makes to enhance our own creativity and the effectiveness of our institutions? 
Forests think. I want to take this seriously, and I want to ask, What are the implications of this claim for our understandings of what it means to be human in a world that extends beyond us?

Wait. How can I even make this claim that forests think? Shouldn't we only ask how people think forests think? I'm not doing this. Here, instead, is my provocation. I want to show that the fact that we can make the claim that forests think is in a strange way a product of the fact that forests think. (Kohn 2013:21-22)

I perhaps should have left well enough alone, for the Taylor example illustrates the point, but recognizing that anthropology routinely faces issues like that raised by Kohn, it seems to me a useful exercise to regularly think again about how very differently people, of varied human cultures, set the limits of what is real and what is not, what may or could or could not possibly be. Anthropologists appreciate better than anyone that our own thinking is as culturally embedded as that of anyone we study, and we shouldn't be surprised that some of our most fundamental notions derive from current Western belief systems, not themselves directly from irrefutable scientific facts.

And finally, as my last example of well-known ways culture makes a difference to human beings, it is often said that culture breaks us free from biology. This is true in important ways, but the relationship between biology and culture is not as easy to sort out, I think, as some suggest. For example, when we speak of cultural evolution, to what extent is this, should this be, meant as merely an analogy to biological evolution, or instead as part of the same phenomenon? This question has not been answered to the satisfaction of all, and for this reason it is not easy to agree upon answers to such questions as how we should measure "fitness" in cultural evolution compared to biological. Ask anyone working in cultural evolution today about their work and odds are you will get a clear and often firm answer concerning how to measure fitness. But it won't be the same answer their colleague gives. There are some scholars who believe we should use standard biological approaches (number of offspring who live to reproductive age), others lean more toward some indication of quality of life. No doubt there are other possible choices. What we each prefer may well connect with what we think about the degree to which culture is separate from biology.

Central to this question is the matter of the degree to which our cultures free us from natural selection. Here there is probably more agreement; it is hard to imagine any living organism actually free from the pressures of natural selection. Yet our cultures do change the way natural selection works on us, as for example in insulating individuals from certain kinds of selection pressures, making a very big difference in the course of evolution for the species as a whole. Overall, discussion of the relationship between biological and cultural evolution has a long history in anthropology. Here I want to bring up Alfred Kroeber again, who wrote quite a bit about culture, including a classic article titled The Superorganic. It was published in American Anthropologist in 1917 and is often reprinted. It's long, tedious, and to the modern ear seems to careen back and forth between the obvious and the obscure. I love it. I would even suggest a celebration of its $100^{\text {th }}$ anniversary if I could find a second person to agree.

Early on Kroeber uses as an example, the nature of adaptation to living in the arctic. The polar bear had thick fur, for example, but for all the generations the Eskimo have lived in these icy regions, they have not grown body hair beyond that of everyone else. Instead they build tightly closed houses. (Did I mention some of it seems obvious?) Importantly, though, he goes on to argue that the difference between the bear and the human is not, in fact, the seemingly obvious difference between body and mind. It is not our superior human intelligence, in itself, that makes the difference, but rather a distinction between the organic and the cultural, which Kroeber notes is a difference of kind, not degree (1952:27). ${ }^{4}$

Yet, in another sense, nothing humans do is really separate from our biology. Hans Jonas, who is one of my favorite philosophers-and not just because I can sometimes understand him-pointed out in The Phenomenon of Life that if we are to understand the world of life, we must account for all of life. Humans are as much a part of the living world as bacteria, and an understanding of the living world that focuses on simpler life forms, and considers human adaptations, such as cumulative culture, as an aberration, does not do justice to what life is.

\section{Culture has Made Us Human}

At one time, the academic consensus was that culture was for humans only, though as with so many big questions, there had always been dissenters. A major turning point came in 1960, when Jane Goodall observed two chimpanzees at the Gombe field site in Tanzania pick up small twigs, strip off the leaves, and use them as tools to fish for termites in the ground, which they ate as a kind of high-protein gorp. Ethologists and anthropologists had thought only humans used and made tools; Homo sapiens-Man the

\footnotetext{
${ }^{4}$ As a technical note, I need to mention that he uses here the word "social" rather than "cultural" at this point, but I believe he is talking about culture.
} 
Toolmaker was the prevailing view. Thus, Louis Leakey's famous response to Goodall's telegram was: "Now we must redefine tool, redefine Man, or accept chimpanzees as humans."

And he was right. But fifty odd years later, scholars are still debating which of these things we should redefine. As someone interested in the spiritual side of reality, my own first choice is redefining the human. Defining us as tool users never really got to the heart of it. Even accepting, as many scholars did that this is something that makes us unique, it could not be more than a small part of the story. But decades later, when it at last became widely accepted that non-humans are cultural animals as well, that very important step was taken largely by redefining culture instead of redefining the human. Using the spare but legitimate definition of culture as "patterns of behavior transmitted socially" people began to realize that it could reasonably be argued that many different kinds of organisms have culture.

Why is it important that other animals besides humans are cultural beings? Recognizing that some non-human animals have cultures helps us appreciate that almost certainly our pre-human ancestors did as well. It is certain that tool use goes back at least as far as Homo habilis, very likely further. And there is growing evidence that what we take to be some of our most important human traits can be found among earlier hominins like Homo naledi who appears to have engaged in burial practices (Berger 2015; Berger and Hawkes 2017). And this isn't just a fun science fact of the day. It changes our view of our own origins. It means it is entirely possible that culture helped shape us as humans, rather than coming later as a kind of marker of our humanity.

It's not that culture is the cause, singular, of the human mind and its unique capacities, rather that early and simple pre-human cultures comprised an essential part of an iterative process leading to us and to who knows what in the future. Michael Tomasello played a very important role in our coming to appreciate this point through his 1999 book with the giveaway titleThe Cultural Origins of Human Cognition (see also Laland 2017). Tomasello nicely summarizes the three main factors involved-the ability to see fellow conspecifics as intentional and mental beings like ourselves, the development of new forms of cultural learning with active, not just passive, modes of social transmission, and the fact that humans have an extended juvenile phase during which we indulge in learning while growing up in rich cultural environments.

Cumulative culture requires not just creative invention but faithful social transmission, and it is a surprising fact that it is the faithful social transmission part that appears to be the unique strength of humans. Chimpanzees have no trouble with the creative part as mentioned earlier, but they rely almost exclusively on imitation and observation for social transmission. However, by human standards these methods are very passive, not to mention ineffective, compared to the great importance humans put on active teaching in virtually any setting, on any topic, at any time.

\section{Culture Can Help Explain our Minds}

Now I turn from situations in which the phenomenon of culture makes a difference for humans and for the world of life on this planet, to ones in which the concept of culture can be used as a descriptive and analytical tool in addressing old and intractable questions far beyond anthropology proper. Neurobiological work, including efforts to correlate elements of thought with parts of the brain, has led many of those engaged in this scientific work as well as some philosophers, to a perspective often referred to as reductive physicalism. We are told, for example, that we are not really conscious, or, perhaps less dramatically, that consciousness is not what we think it is, that it is not nearly as important for our behavior as we imagine. We learn that our desires, plans and moral decisions do not have the causal role in affecting our actions that we believe they do based on our subjective experience. A few quotes from a popular book on the subject, provocatively titled Who's in Charge?, by a leading neuroscientist, Michael Gazzaniga, will illustrate-not because he is by any means extreme in his views, far from it-but rather because he writes so clearly. Gazzaniga states: "From this brain comes our personal narrative, not from some outside mental forces compelling the brain" (2011:41). He then addresses the question most of us ask in the face of such conclusions-"Does the person who believes that the human mind, its thoughts, and resulting actions are determined, actually feel any different than anyone else?" and goes on to suggest that the answer is 'no'.

No doubt you will still feel pretty much in control of your brain, in charge, and calling all the shots. You will still feel that someone, $\underline{y o u}$, is in there making the decisions and pulling the levers. This is the homuncular problem we can't seem to shake: The idea that a person, a little man, a spirit, someone is in charge. Even those of us who know all the data, who know that it has got to work some other way, we still have this overwhelming sense of being at the controls. (Gazzaniga 2011:41)

Many others have made essentially the same point, drawing on a range of studies such as the Libet experiments from the 1980s. Mele notes that Libet is the one person who "is cited more often than anyone else by scientists who claim that free will is an illusion" 
and that it is "often said that Libet proved we make all our decisions unconsciously and therefore never decide anything of our own free will” (2014:8). These studies seemed to show that the brain was already making a decision a brief period before the time subjects indicated as when they were aware of making the decision. This work has often been thought to show that what we take to be conscious decisions are already settled before we become conscious of them.

These findings are difficult to reconcile with the sense that we are the conscious authors of our actions. One fact now seems indisputable: Some moments before you are aware of what you will do next-a time in which you subjectively appear to have complete freedom to behave however you please-your brain has already determined what you will do. You then become conscious of this "decision" and believe that you are in the process of making it. (Harris 2012:9)

Harris concludes: "What will my next mental state be? I do not know-it just happens. Where is the freedom in that?" (ibid.). Over the past decade or so a more nuanced approach has become much more common, with critiques of these strong conclusions by Dennett (2003) and Mele (2014) being particularly valuable. Even Libet (for example, 2005) did not accept the Harris kind of interpretation of his work. Nevertheless, much other experimental work, performed with equipment capable of far greater precision than was available to Libet in the 1980s, has also shown how closely connected our various kinds of thoughts are to the functioning of specific parts of our brains. And, as noted above, there are many who, like Gazzaniga, believe we have no choice but to conclude that in important respects our conscious experience of being a self in control is an illusion, even, one must presume, when writing a book about not being in control.

This last point is neither a new nor a frivolous concern. The basic problem (in the context of the evolution of mind) was brought up by Darwin who observed:

But then with me the horrid doubt always arises whether the convictions of man's mind, which has been developed from the mind of the lower animals, are of any value or at all trustworthy. Would any one trust in the convictions of a monkey's mind, if there are any convictions in such a mind? (Darwin 1881)

We might reply to Darwin, as has often been done, that he seems perfectly capable of having conviction concerning the theories produced by his own mind. Pointing out this irony alerts us to a serious problem, for surely both Gazzaniga and Darwin have a point even if it also undermines their own thinking as much as any other. It is possible, however, that an appreciation for the difference culture makes might help.

How might a consideration of culture help us to understand the mind-brain relationship, along with what the mind really is? Culture could make a difference for these discussions, because it is easier, in the face of this fascinating and ever-growing set of empirical data, to dispute the existence of a mind, or to limit it to a function of the brain, than it is to dispute the independent existence of culture. Culture cannot be reduced to an epiphenomenon of anyone's brain, for the simple reason that it is shared by every adherent of the culture in question.

If we assume (for the moment) that cephalopods are not cultural beings, we can say that there are currently no known examples of cultural beings who do not have brains, making it reasonable to accept the general assumption that there would be no such thing as culture without highly complex brains. But the connection between cultural traditions and individual brains is not nearly as close as between individual brains and individual minds, and to the extent there is a connection, it cannot be seen as a one-way street, rendering any argument concerning culture that is parallel to brain-mind arguments based on the closeness of mental activities to elements of the brain, far less plausible. Culture is real, it is non-material, and it can't be reduced to an epiphenomenon of an individual's brain, yet it can influence what happens in the material world, such as the kind of food I choose to prepare for my dinner vs. the kind of food someone in a village in India will eat this evening. And if some nonmaterial phenomenon has causal efficacy in the material world, perhaps it becomes more likely that another, the human mind, can as well.

\section{Culture Helps Make Sense of Altruism in Evolution}

The fourth situation illustrates one way in which culture is currently being used to help solve a serious

\footnotetext{
${ }^{5}$ See Roediger et al. (2008:208-209) for a nice review of Libet, including his idea that while we may not have free will, we do have "free won't," the ability to consciously veto decisions made unconsciously.
} 
biological conundrum, the problem of how altruism could evolve. David Sloan Wilson defines altruism as "a concern for the welfare of others as an end in itself," without expectation of reward (Wilson 2015). In other definitions, to qualify as altruism a behavior would require an actual sacrifice of time, resources or self, on behalf of another. Either description works for our purposes.

The advent of altruism has occupied a prominent role in Darwinian thought because it is difficult to explain as a product of natural selection. If natural selection is an unrelenting competition favoring traits that cause some individuals to survive and reproduce better than other individuals, and if altruistic behavior increases the survival and reproduction of those "others" at the expense of the altruist, then altruistic traits should be weeded out.

One approach, common from the 1960 s and something you will still hear today, is to argue that altruism simply cannot evolve. What we take to be altruism is really selfishness in disguise. We can imagine one individual helping another who is closely-related genetically, but only because the second individual's genes are nearly identical to one's own. In that case, as far as fitness is concerned, such an act is essentially helping oneself. It is close enough to self-preservation to be selected for, on the one hand, but only by a stretch can it be considered care for another.

Individuals might be observed to help others who are further away genetically, but that too is bound to be selfishness in disguise. It has to be, right? No doubt an action that seems to be other-regarding is actually performed with expectation of return, as in "reciprocal altruism” or more indirectly via cultural factors such as enhanced prestige which would eventually bring benefits far in excess of what was given initially. Michael Ghiselin put this famously in 1974 as follows:

No hint of genuine charity ameliorates our vision of society once sentimentalism has been laid aside. What passes for co-operation turns out to be a mixture of opportunism and exploitation...Given a full chance to act in his own interest, nothing but expediency will restrain [a person] from brutalizing, from maiming, from murdering-his brother, his mate, his parent or his child. Scratch an "altruist" and watch a "hypocrite" bleed. (Quoted by Wilson 2015:33)

According to this approach to the problem, even those who have done me great kindness were really being selfish, and would instead have brutalized me if not for some expedient quirk of our sociality that has made helping me a quicker way of achieving selfish ends than killing me! So, for these theorists, culture is just convenient means to a selfish end. But I think culture is important in a different way than this view suggests. Yes, hypocrisy is more than common enough, and yes we are capable of convincing ourselves we are being altruistic when we are actually being selfish. But could the view expressed in this quote, widely held if not always stated with such clarity, be taken not as an inevitable consequence of selection, but as a reductio ad absurdum for the whole selfish gene line of thought from which it grows? In point of fact, this specific idea and the negative view of reality painted by self-genism in general, is based on two major errors: denying the reality of group selection and denying the significance of culture-and together, cultural group selection.

In a very helpful recent article, Joan Silk and Bailey House (2016) review a wide range of evidence for altruistic behavior among non-human primates, confirming what we might expect, that it is of a very different order from human altruism. Multiple studies have shown that when monkeys or even apes are given an opportunity to aid another individual they usually do not. This is true even if there is no cost to themselves, and even if the other individual was someone they knew and liked (anyway, tended to get along with).

It is true that among species in which parenting is shared by those who are not the parents, individuals did display some prosociality. Still, Silk and House point out that among cooperatively breeding mammals (not just primates) most helpers are closely related to the infants, suggesting that kin selection could play a role in the evolution of cooperative breeding. Which is to say, this is behavior that could be a product of natural selection. They conclude: "Thus, in non-human primates, high levels of allomaternal care and prosociality may be a product of selection favoring altruistic behavior toward kin" (2016:5).

This is very much what anyone holding a view of evolution emphasizing competition and natural selection on individuals alone might well expect. For individuals to help those who are closely related and have a high percentage of the same genes is little different from helping oneself directly. And it is natural to build from there to suggest that altruism and prosociality might well have the same basis among humans. But, while I believe this could help explain the origins of the practice, prosociality is very different among humans. For example, we cooperate well beyond genetic kin; very likely you have done so today already. This means our altruistic behaviors cannot be attributed simply to shared parenting or to kin selection.

Wilson (2015) identifies the role that cultural group selection plays in the evolution of behaviors, and in the case of humans, ideas, that would not plausibly evolve if one took a more individualist perspective. Groups in which individuals are more willing to share foods, and to help in other ways are more likely to thrive than groups composed mostly of individuals who do not 
cooperate in these ways. Such behaviors are based on cultural rules and expectations, so this is a cultural group selectionist argument in that the cultural traits help a group gain competitive selective advantage. As noted earlier, it is not very likely that culture is completely separate from, or has separated us, from biology, and to say that behaviors are based on cultural rules is not to say they are uninfluenced by our biology. But it does indicate the role that culture can play in shifting the unit of selection from individual to group. And of course cultures have established "norms" of behavior that can influence our actions, overcoming to a greater or lesser extent what our mental and hormonal systems might otherwise lead us to.

Neither Wilson nor I are suggesting that culture makes everyone good and selfless. Does a hunter who shares his game do so out of the goodness of his heart, because it is simply expected, or perhaps because it builds a reputation which can be "cashed in" for any number of perks? The hunter may or may not be reducing his or her individual fitness, and I won't vouch for what you would find if you scratched him. However, this situation is very different from the harsh and blind law of the jungle, for cultural rules, and broadly, cultural group selection, can allow the evolution of genuine altruism-an individual helping fellow group members who are not all closely related-and exchanges that are genuinely cooperative. Even if some-even if manyexchanges are done for selfish reasons or done grudgingly out of cultural expectation, altruism is likely to be fostered, for these things can increase the group's fitness overall and with it, the fitness of every group member, including those who made the sacrifices.

Interestingly, this isn't a new idea. What Silk, House and Wilson have done is brought renewed respectability and empirical support to an idea originally presented in 1871 .

...although a high standard of morality gives but a slight or no advantage to each individual man and his children over other men of the same tribe, yet... an increase in the number of well-endowed men and an advancement in the standard of morality will certainly give an immense advantage to one tribe over another. A tribe including many members who, from possessing a high degree of the spirit of patriotism, fidelity, obedience, courage, and sympathy were always ready to aid one another, and to sacrifice themselves for the common good, would be victorious over most other tribes. (Darwin 1896 [1871]:132)

This issue of tribes supplanting other tribes is a kind of dark side of altruism. Darwin is suggesting that as populations increase, competition among groups will favor the spread of cultural norms that enhance the welfare of the group and make it more successful in intergroup competition. In other words, competition at one level can foster cooperation at another level. This is great in so far as it helps individuals contribute altruistically to the group, but to the extent that intragroup cooperation, sacrifice for the greater good, is based on an 'us-against-them' competition, it will eventually also contribute to limiting the range of cooperation. The ability to foster genuine cooperation and altruism is a benefit of competition among groups, but as we know, not all consequences of inter-group competition are so positive.

\section{Culture is the Medium through which We Know God}

Finally, the concept of culture can prove useful in our understanding of our relationship to God. Religion, by definition, is a human phenomenon-a group's beliefs and practices oriented to the divine or supernatural world. It is God who is sacred, not religion, the latter is part of culture. Yet, to the extent that our religion enriches our sense of transcendence and to the extent, more especially, that it helps us open up to God, this element of culture may be the most important of all the differences that culture makes.

Human intelligence is also important for communicating with God, of course. For example, it could be argued that one can only really love another to the extent that one knows him or her. Greater intelligence allows us to know more about God and to know God more, and thus provides us with a greater capacity for love than we would have without our human level of intelligence. Not that we always take advantage of it, of course, but still, it is possible that this is one reason (in the sense of purpose or "final cause") for the unique cognitive capacities of humans.

I am not sure culture is needed for communication with God in the same sense, but it is necessary in the sense that since we are cultural beings, and since for humans, our cultural nature includes living in symbolic worlds, everything that comes in or out is filtered by the fundamental understandings of reality and of what is proper, provided by our culture. Some of the implications are well known:

- We can study religion as a cultural phenomenon, something explicitly proposed by Tylor a century and a half ago as being distinct from theological approaches, and that has been very productive.

- We can acknowledge that the enlightenment ideal of humans pursuing a God's eye objective view of reality is just not possible. We are cultural beings and as much as our cultures enable thought, they also channel it in ways we don't fully realize. And 
this includes thought about God. That is, our thought might be about the creator of the universe, but it is still the thought of an enculturated physical being.

- And, as has been explored in some depth by people like Andrew Walls-we can accept the fact that even revelation from God mostly comes to us through culture. The Gospels provide a narrative of events that took place in a specific time and place, and we, in another time and place, seek to learn from them. This means there are at least two layers of culture, you might say, between any hypothetical, encompassingly objective God's eye view and our own.

Putting it this way might sound discouraging. But I would like to suggest an approach that, instead of just bemoaning the fact that even the Gospel reaches us through a cultural filter, seeks to take advantage of this situation. It also takes advantage of the fact, well known to Amos Yong and several generations of anthropologists, that cultures are not coherent wholes, hermetically sealed from each other. And finally, it draws on the question with which I began-to what extent are each of us part of overlapping cultural traditions-Christian culture, and East-Coast suburban American, say.

Suppose we were to use cross-cultural study of human thought on a focused subject much more explicitly and systematically than we have to date, not just for understanding those cultures in themselves, but also as a means of taking us a step closer to universal knowledge, or at least helping us look at something through slightly different eyes. We can do more, I think, to overcome the limitations of any one cultural perspective by taking advantage of cultural differences rather than trying to eliminate them.

For example, theology and biblical studies are fields in which the insights and conclusions of different scholars might well differ due to their cultural backgrounds. Coming from the sciences, my initial response to that situation is something like, "Too bad, then it can't really be objective!” But there is a positive side as well, one that might ultimately be better as a way of gaining insight into biblical passages and theological questions than would be possible for scholars from any one cultural tradition alone.

The hard work is already underway and has been, to varying degrees, for a long time. In fact, there are Christian theologians engaged in solid and creative scholarship in many parts of the world, possibly everywhere. Materials and well-trained scholars are available. But as far as I know, few attempts have been made to bring these scholars and their ideas together and to undertake the difficult task of exploring how the culturally-originating differences in their conclusions can be used for taking a step closer to a common understanding of the truth.

\section{A Final Note, Mostly on the Future}

Linguist and anthropologist Daniel Everett notes that most of us well appreciate the fact that if we had been raised in a different culture, we would be different people. Different physically, mentally, morally and perhaps in other ways. Anthropology brought this to our attention and has provided a vast amount of information-importantly, insight as well as information-on the range of these differences and on how they come about. But Everett believes, and I am inclined to agree, that we have much more to learn about the difference culture makes for us as humans. Everett is developing a linguistic and cognitive argument suggesting that culture shapes much more of our thinking than we even now appreciate, forming us in what he calls "dark matter of the mind" (Everett 2016).

The question, how different would we be if we were raised in a different culture?, also brings to mind the question being asked in new ways today, how different can we be if we put our minds to it? I believe the answer here, paralleling Everett's answer to the first question, is that we can be more different, cultures can be more disparate, than we usually imagine. This is important, for it is far easier to intentionally change our cultures than our biology in directing the course of our own evolution.

Importantly, very importantly I believe, we can change, intentionally or otherwise, nearly any aspect of our cultures we wish to alter. And as we come to appreciate how important our cultures are to who we are, the many important differences they make, it would seem that we can intentionally make far greater differences in our lives than we have previously imagined. So, the more we appreciate what a great difference culture makes, the more we must also appreciate how important it is to come to know what those differences are and how they work.

\section{References}

Berger, Lee, and John Hawkes. 2017. Almost human. Washington, DC: National Geographic.

Berger, Lee, et al. 2015. Homo naledi, a new species of the genus Homo from the Dinaledi Chamber, South Africa. eLife 2015;4:e09560.

Boyd, Robert, and Peter J. Richerson. 1985. Culture and the evolutionary process. Chicago: University of Chicago Press.

Chaput, Charles J., 2017. Strangers in a strange land: living the Catholic faith in a post-Christian world. New York: Henry Holt and Company. 
Crouch, Andy. 2016. Views: The myth of 'engaging the culture'. Christianity Today 60(6):33-34.

— 2013. Culture making: recovering our creative calling. Downer's Grove, IL: InterVarsity Press.

Darwin, Charles. 1896 [1871]. The descent of man and selection in relation to sex. Revised, authorized edition. New York: D. Appleton and Company.

—. 1881. Letter to William Graham, July 3. Darwin Correspondence Project. Letter no. 13230.

Dennett, Daniel. 2003. Freedom evolves. New York: Viking Press.

Donald, Merlin. 1991. Origins of the modern mind: three stages in the evolution of culture and cognition. Cambridge, MA: Harvard University Press.

Dreher, Rod. 2017. The Benedict option: a strategy for Christians in a post-Christian nation. New York: Sentinel.

Esolen, Anthony. 2017. Out of the ashes: rebuilding American culture. Washington D.C.: Regnery Publishing.

Everett, Daniel L. 2016. Dark matter of the mind: the culturally articulated unconscious. Chicago, IL: University of Chicago Press.

Gazzaniga, Michael. 2011. Who's in charge?: Free will and the science of the brain. New York: Ecco.

Geertz, Clifford. 1973. The interpretation of cultures. New York: Basic Books.

Harris, Sam. 2012. Free will. New York: Free Press.

Jonas, Hans. 2001 [1966]. The phenomenon of life: toward a philosophical biology. Evanston, IL: Northwestern University Press.

Kendal, Rachel, Lydia M. Hopper, Andrew Whiten, Sarah F. Brosnan, Susan P. Lambeth, Steven J. Schapiro, and Will Hoppitt. 2015. Chimpanzees copy dominant and knowledgeable individuals: implications for cultural diversity. Evolution and Human Behavior 36:65-72.

Kohn, Eduardo. 2013. How forests think: toward an anthropology beyond the human. Berkeley: University of California Press.

Kroeber, Alfred. 1952 [1917]. The superorganic. Reprinted in The Nature of Culture. Chicago, IL: The University of Chicago Press.

Kroeber, Alfred, and Clyde Kluckhohn. 1952. Culture: A critical review of concepts and definitions. New York: Vintage Books.

Laland, Kevin N. 2004. Social learning strategies. Learning and Behavior 32:4-14.

—. 2017. Darwin's unfinished symphony: how culture made the human mind. Princeton, NJ: Princeton University Press.

Libet, Benjamin. 2005. Mind time: the temporal factor in consciousness. Cambridge, MA: Harvard University Press.

Mele, Alfred R. 2014. Free: why science hasn't disproved free will. Oxford, UK: Oxford University Press.

Renfrew, Colin and Chris Scarre, eds. 1998. Cognition and material culture: the archaeology of symbolic storage. Cambridge: McDonald Institute for Archaeological Research.

Roediger, Henry L. III, Michael K. Goode, and Franklin M. Zaromb. 2008. Free will and the control of action. In Are we free? Psychology and free will. John Baer, James C. Kaufman, and Roy F. Baumeister, eds. Pp. 205-225. Oxford, UK: Oxford University Press.
Silk, Joan B., and Bailey R. House. 2016. The evolution of altruistic social preferences in human groups. Philosophical Transactions of the Royal Society B 371(1687).

Taylor, Charles. 2007. A secular age. Cambridge, MA: Harvard University Press.

Tomasello, Michael. 1999. The cultural origins of human cognition. Cambridge, MA: Harvard University Press.

- 2014. A natural history of human thinking. Cambridge, MA: Harvard University Press.

Watson, Stuart K., Lisa A. Reamer, Mary Catherine Mareno, Gillian Vale, Rachel A. Harrison, Susan P. Lambeth, Steven J. Schapiro, and Andrew Whiten. 2017. Socially transmitted diffusion of a novel behavior from subordinate chimpanzees. American Journal of Primatology 79(6).

Whiten, A., J. Goodall, W. C. McGrew, T. Nishida, V. Reynolds, Y. Sugiyama, C. E. G. Tutin, R. W. Wrangham and C. Boesch. 1999. Cultures in chimpanzees. Nature 399:682-685.

Wilson, David Sloan. 2015. Does altruism exist. ${ }^{\text {C Culture, }}$ genes, and the welfare of others. New Haven, CT: Yale University Press and Conshohocken, PA: Templeton Press.

Yong, Amos. 2003. Beyond the impasse: toward a pneumatological theology of religions. Grand Rapids, MI: Baker Academic. 